\title{
ГОРМОНАЛЬНО-НЕАКТИВНЫЕ ОБРАЗОВАНИЯ НАДПОЧЕЧНИКОВ В УСЛОВИЯХ РАБОТЫ ВРАЧА-ЭНДОКРИНОЛОГА ПОЛИКЛИНИЧЕСКОГО ЗВЕНА
}

\author{
Чжен Т.Р., Киселева Т.П. \\ ФГБОУВО «Уральский государственный медицинский университет» МЗ РФ, Екатеринбург
}

ЦЕЛЬ: оценить признаки злокачественного потенциала гормонально неактивных образований надпочечников в условиях работы врача поликлинического звена.

МАТЕРИАЛЫ И МЕТОДЫ: 56 пациентов с гормонально-неактивными образованиями надпочечников (ГНОН) наблюдаются амбулаторно в поликлинике ГКБ №40. Статистический анализ результатов исследования выполнен с помощью программы Microsoft Excel 2010 года. Количественные признаки описывались как $\mathrm{M} \pm \mathrm{SD}$. За критический уровень значимости принимались значения $\mathrm{p}<0,05$.

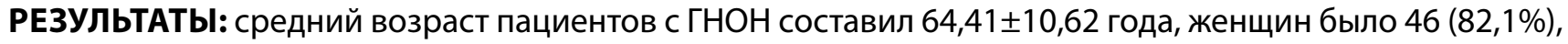
мужчин - 10 (17,9\%). Локализация ГНОН в правом надпочечнике - 14(25\%), в левом - 28 (50\%), била-

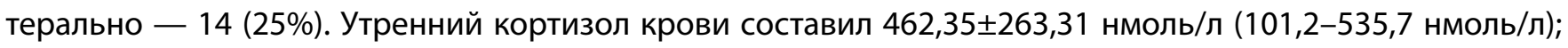

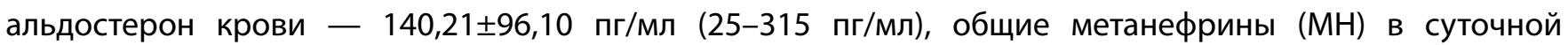

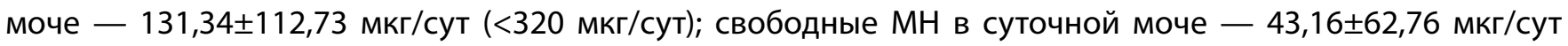
(20-345 мкг/сут), норметанефрины (НМ) общие в суточной моче - 183,86 $\pm 312,14$ мкг/сут (<390 мкг/сут),

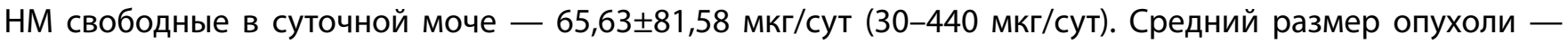
$2,44 \pm 1,45$ см, период наблюдения $-5,27 \pm 3,05$ лет. По КТ плотность образований в нативную фазу (НФ) варьировала от - 69 до $+50 \mathrm{HU}$, медиана $6 \pm 26 \mathrm{HU}$, в артериальную фазу (АФ) медиана $72 \pm 24 \mathrm{HU}$, в венозную фазу (ВФ) медиана $55 \pm 23 \mathrm{HU}$, в отсроченную фазу (ОФ) на 6 минуте медиана $27 \pm 11 \mathrm{HU}$.

Выводы: большую часть среди ИН занимают ГНОН, у женщин встречается чаще, чем у мужчин, уровень гормонов при ГНОН в пределах нормальных показателей. Размер образований менее 2,44см, низкая нативная плотность по КТ являются признаками низкого злокачественного потенциалаГНОН.

КЛЮЧЕВЫЕ СЛОВА: инциденталома надпочечника, гормонально-неактивное образование надпочечников. 